Tropical Journal of Pharmaceutical Research December 2020; 19 (12): 2659-2666

ISSN: $1596-5996$ (print); 1596-9827 (electronic)

(C) Pharmacotherapy Group, Faculty of Pharmacy, University of Benin, Benin City, 300001 Nigeria.

Original Research Article

http://dx.doi.org/10.4314/tjpr.v19i12.26

\title{
Quality comparison of traditional Chuanxiong produced in Dujiangyan City and Sichuan ProvinceC and Chuanxiong from other areas, based on analysis of volatile oil, total alkaloids and total ferulic acid contents
}

\author{
Ling Chen ${ }^{1}$, Jia Hou², Wei Deng', Guihua Jiang ${ }^{1 *}$ \\ ${ }^{1}$ Chengdu University of Traditional Chinese Medicine, Chengdu $611137,{ }^{2}$ College of Pharmacy, Gansu University of Chinese \\ Medicine, Lanzhou 730000, China
}

*For correspondence: Email: 11469413@qq.com

Sent for review: 2 June 2020

Revised accepted: 25 November 2020

\begin{abstract}
Purpose: To compare the qualities of Chuanxiong from different production areas (authentic and traditional production areas in Dujiangyan, Sichuan Province) and other non-authentic production areas, as well as different germplasm sources, using a combination of methods.

Methods: A fingerprint spectrum of volatile oils was established, and the qualities of the chuanxiong samples were compared using gas chromatography (GC), while gas chromatography-mass spectrometry (GC -MS) was used to analyze the chemical compositions of the volatile oils.

Results: There were significant differences in the chemical compositions of volatile oils of Chuanxiong from different plants. Most of the qualities of Chuanxiong were higher after transplantation to the germplasm nursery at Dujiangyan, Sichuan. There was increase in the contents of total alkaloids and total ferulic acid in some chuanxiong transplanted to the germplasm nursery.

Conclusion: This is the first study that compares the quality of Chuanxiong from different producing areas using a combination of several methods. These methods are feasible and effective, and the results provide a reference for research on standardization and quality control of Chuanxiong.
\end{abstract}

Keywords: Chuanxiong, Volatile oil, Total alkaloids, Ferulic acid, Fingerprint, Dujiangyan City

\begin{abstract}
This is an Open Access article that uses a fund-ing model which does not charge readers or their institutions for access and distributed under the terms of the Creative Commons Attribution License (http://creativecommons.org/licenses/by/4.0) and the Budapest Open Access Initiative (http://www.budapestopenaccessinitiative.org/read), which permit unrestricted use, distribution, and reproduction in any medium, provided the original work is properly credited.
\end{abstract}

Tropical Journal of Pharmaceutical Research is indexed by Science Citation Index (SciSearch), Scopus, International Pharmaceutical Abstract, Chemical Abstracts, Embase, Index Copernicus, EBSCO, African Index Medicus, JournalSeek, Journal Citation Reports/Science Edition, Directory of Open Access Journals (DOAJ), African Journal Online, Bioline International, Open-J-Gate and Pharmacy Abstracts

\section{INTRODUCTION}

Chuanxiong rhizoma (chuanxiong) is derived from the dried rhizome of Ligusticum chuanxiong Hort [1], which was first recorded in Shen Nong's classic of Materia medica. Chuanxiong originated in the Song dynasty and was considered better than others in ben cao tu jing which was written by Su song. It was the first time of appearance of "chuanxiong" instead of "xiongqiong" in the contents of tang ye ben cao during Yuan dynasty [2]. Guanxian (now Dujiangyan, Sichuan Province, China) gradually became the main producing area of chuanxiong from the Song dynasty, according to the textual research. Chuanxiong is a cultivated breed which resources are rich and widespread. It is produced mainly in Dujiangyan, Pengzhou, 
Chongzhou, and Xindu, Sichuan Province, China. Chuanxiong is also cultivated in Yunnan, Jiangxi and Gansu Provinces, China. Chuanxiong from different places differ in quality. The quality of Chinese medicine is important for ensuring the safety and effectiveness of clinical medication. Therefore, there is a clear need for production of high-quality chuanxiong. In this study, chuanxiong samples were collected from different sources and the chemical compositions of their volatile oils were determined. Then, the contents of volatile oil, total alkaloids, and total ferulic acid in chuanxiong from different origins were compared. In addition, comparisons were made between the contents of volatile oil, total alkaloids, and total ferulic acid in chuanxiong from their original sources, and the contents of these components after transplantation of the chuanxiong resources to the germplasm nursery in Dujiangyan, Sichuan Province.

\section{EXPERIMENTAL}

\section{Chemicals and reagents}

Reference standards of (+) - camphor, ligustrazine hydrochloride and ferulic acid were purchased from National Institute for Food and Drug Control (Beijing, China). Chloroform, bromothymol blue, acetonitrile, xylene, glacial acetic acid, anhydrous sodium sulfate and sodium bicarbonate were purchased from Chengdu Kelong Chemical Reagent Factory (Chengdu, China). Chuanxiong samples were collected from Sichuan, Yunnan, Jiangsu, Jiangxi, Gansu, Guizhou and Jilin, and were identified by Professor Yuying Ma of Chengdu University of TCM, Chengdu, China. All samples from different chuanxiong producing areas were preserved in the germplasm nursery. In all, a total of 16 samples were analyzed, as shown in Table 1.

Table 1: Chuanxiong samples used, and their sources

\begin{tabular}{ll|cl}
\hline No. & Place of origin & No. & Place of origin \\
\hline 1 & Dujiangyan, Sichuan & 9 & Chongzhou, Sichuan \\
2 & Dujiangyan, Sichuan & 10 & Chongzhou, Sichuan \\
3 & Dujiangyan, Sichuan & 11 & Nantong, Jiangsu \\
4 & Pengshan, Sichuan & 12 & Yulong, Yunnan \\
5 & Pengshan, Sichuan & 13 & Heqing, Yunnan \\
6 & Xindu, Sichuan & 14 & Heqing, Yunnan \\
7 & Pixian, Sichuan & 15 & Ruichang, Jiangxi \\
8 & Shifang, Sichuan & 16 & Huating, Gansu \\
\hline
\end{tabular}

\section{Determination of volatile oils}

The volatile oil contents of the chuanxiong samples were determined according to the procedure outlined in Chinese Pharmacopoeia, 2015 edition, volume IV.

\section{Determination of total alkaloids}

Total alkaloids were determined according to the method outlined in Chinese Pharmacopoeia, 2015 edition, volume IV.

\section{Determination of total ferulic acid content}

\section{Instrumentation and separation conditions}

Total ferulic acid content was determined with high performance liquid chromatography (HPLC) performed on Waters 2695 HPLC instrument (Waters, UK) equipped with a diode array detector (DAD) detector, and a Kromasil C18 column $(4.6 \mathrm{~mm} \times 250 \mathrm{~mm}, 5 \mu \mathrm{m})$.

The mobile phase was composed of acetonitrile (A) and $1 \%$ glacial acetic acid aqueous $(B)$ with a volume ratio of $18: 82$. The flow rate was $1.0 \mathrm{~mL} / \mathrm{min}$, and injection volume was $10 \mu \mathrm{L}$. The temperature of column was set at $30{ }^{\circ} \mathrm{C}$. Ferulic acid was monitored at a wavelength of $320 \mathrm{~nm}$ [3].

\section{Sample preparation}

Chuanxiong was ground into powder, and $0.5 \mathrm{~g}$ of the powder was dissolved in $25 \mathrm{~mL}$ of a solution comprised of methanol and $2 \%$ sodium bicarbonate (the volume ratio was 95:5). Ultrasonic extraction was carried out for $100 \mathrm{~min}$. The solution was cooled to room temperature and loss in volume was made up for with $2 \%$ sodium bicarbonate. The mixture was filtered through a $0.45 \mu \mathrm{m}$ filter before injection.

\section{Preparation of standard solutions}

An appropriate amount of ferulic acid was weighed accurately and dissolved in methanol glacial acetic acid (99:1 v:v) solution to yield a ferulic acid concentration of $26.56 \mu \mathrm{g} / \mathrm{mL}$.

\section{Validation of method and sample determination}

The HPLC method was employed and the methodology was evaluated for linearity, precision, repeatability, stability and recovery. Five different volumes of the standard solution $(2,6,10,14$ and $18 \mu \mathrm{L})$ were subjected to HPLC analysis. A linear regression equation was drawn with the injection volume as $x$-axis and the peak area as $y$-axis, and it exhibited good linearity. The precision of the method was evaluated by determining the same sample 6 times, while 
repeatability was obtained by analyzing 6 replicates of the same sample. Stability was tested at several time points $(1,2,4$, and $8 \mathrm{~h})$, and the ferulic acid was stable for $8 \mathrm{~h}$. The recovery was analyzed by spiking known quantity of the standard into 6 chuanxiong samples extracted according to sample preparation. The spiked samples were analysed with HPLC. Total ferulic acid was determined in all samples.

\section{GC -MS analysis of volatile instrumentation and GC -MS conditions}

oil,

The GC-MS analysis was performed with HP$6890 / 5973$ GC-MS instrument with hydrogen Flame lonization detector (FID) and an HP-1 MS capillary column $(60 \mathrm{~m} \times 0.25 \mathrm{~mm} \times 0.25 \mu \mathrm{m})$. The mass spectrometer conditions were similar to literature methods, the carrier gas was Helium, and the flow rate was set as $1.8 \mathrm{~mL} / \mathrm{min}$. The split ratio was 1:20. The mass spectrometer was fitted with an El source operated at $30 \mathrm{eV}$ with a source temperature of $260{ }^{\circ} \mathrm{C}$ [3]. Mass spectra were recorded in the full-scan acquisition mode in the range of $\mathrm{m} / \mathrm{z} 20-450 \mathrm{amu}$.

\section{Sample preparation}

Chuanxiong powder (no.7) was precisely weighed $(100 \mathrm{~g})$ and steam-distilled with $300 \mathrm{~mL}$ of water for $6 \mathrm{~h}$ in a round-bottom flask, made up to $2 \mathrm{~mL}$ with xylene, and dried with anhydrous sodium sulfate. Then, $0.15 \mathrm{~mL}$ of internal standard solution was thoroughly mixed with 0.15 $\mathrm{mL}$ of volatile oil extraction solution.

\section{Preparation of Standard Solution}

The reference standard [(+) - camphor] was weighed and dissolved in xylene to yield a concentration of $2.012 \mathrm{mg} / \mathrm{mL}$.

\section{GC fingerprint of volatile oil, instrumentation and separation conditions}

The GC fingerprint determinations were performed using a Waters GC -2014 instrument (Shimadzu, Japan) equipped with a hydrogen FID and a SUPLCO DB-5 capillary column (30 m $\times 0.25 \mathrm{~mm} \times 0.25 \mu \mathrm{m}) . \mathrm{N}_{2}$ was used as the carrier gas and the flow rate was $1 \mathrm{~mL} / \mathrm{min}$. The temperature of detector and the vaporization chamber were $260^{\circ} \mathrm{C}$. The split ratio was $1: 20$, and injection volume was $1 \mu \mathrm{L}$. The GC temperature was programmed as follows: 60 to $110^{\circ} \mathrm{C}$ at a rate of $2.5^{\circ} \mathrm{C} / \mathrm{min}$, and then to $160^{\circ} \mathrm{C}$ at a rate of $10{ }^{\circ} \mathrm{C} / \mathrm{min}$, and finally to $190{ }^{\circ} \mathrm{C}$ at a rate of $1.5^{\circ} \mathrm{C} / \mathrm{min}[3]$.

\section{Sample preparation}

The method of sample preparation for GC fingerprint was identical to that described in GCMS analysis of volatile oil.

\section{Method validation}

The GC methodology was assessed for precision, repeatability and stability. The precision was evaluated by analyzing the same sample 6 times, while repeatability was obtained by determining 6 replicates of same sample. The stability was tested at several time points $(1,2,4$, and $8 \mathrm{~h}$ ), and the sample was found to stable for $8 \mathrm{~h}$.

\section{RESULTS}

\section{Volatile oil contents}

There were no significant differences in contents of volatile oil in chuanxiong samples from different producing areas, except the sample from Jiangxi. The levels of volatile oil in some of the chuanxiong samples were increased after transplantation to the germplasm nursery in Dujiangyan. These results are shown in Table 2.

\section{Total alkaloid contents}

As shown in Table 2, there were no significant differences in the contents of total alkaloids of chuanxiong from the various sources.

\section{Total ferulic acid levels}

The chromatograms of standard ferulic acid and ferulic acid in chuanxiong samples are shown in Figure 1, and the contents of ferulic acid are presented in Table 2.
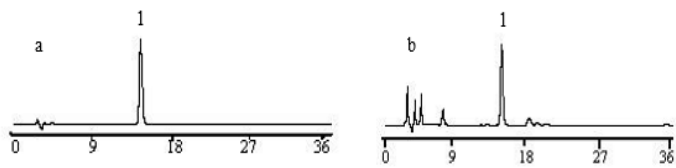

(min)

(min)

Figure 1: Chromatogram of ferulic acid standard (a), and chuanxiong sample (b).

The results in Table 2 show that there were no significant differences in the levels of the main components among the chuanxiong samples, except for samples 4, 11 and 15. In most of the chuanxiong samples, the levels of volatile oil, total alkaloids and total ferulic acid were increased after transplantation to the germplasm nursery in Dujiangyan, Sichuan.

Trop J Pharm Res, December 2020; 19(12): 2661 
Table 2: Levels of volatile oil, total alkaloids and total ferulic acid in Chuanxiong samples

\begin{tabular}{lcccccc}
\hline S/no. & \multicolumn{2}{c}{ Chuanxiong from its place of origin } & \multicolumn{2}{c}{ Chuanxiong } & transplanted to germplasm nursery \\
\cline { 2 - 6 } & $\begin{array}{c}\text { Volatile oil } \\
(\%)\end{array}$ & $\begin{array}{c}\text { Total } \\
\text { alkaloids (\%) }\end{array}$ & $\begin{array}{c}\text { Total ferulic } \\
\text { acid (\%) }\end{array}$ & $\begin{array}{c}\text { Volatile oil } \\
\text { (\%) }\end{array}$ & $\begin{array}{c}\text { Total alkaloids } \\
\text { (\%) }\end{array}$ & $\begin{array}{c}\text { Total ferulic acid } \\
\text { (\%) }\end{array}$ \\
\hline 1 & 0.4050 & 0.2040 & 0.1745 & 0.2500 & 0.2799 & 0.2135 \\
2 & 0.3750 & 0.1946 & 0.1251 & 0.3000 & 0.3234 & 0.2318 \\
3 & 0.3750 & 0.3410 & 0.1145 & 0.4700 & 0.1805 & 0.1577 \\
4 & 0.2650 & 0.1239 & 0.2475 & 0.2400 & 0.1764 & 0.2506 \\
5 & 0.3800 & 0.2545 & 0.2300 & 0.4200 & 0.3182 & 0.1857 \\
6 & 0.3900 & 0.1436 & 0.1874 & 0.4200 & 0.2252 & 0.1983 \\
7 & 0.4400 & 0.2142 & 0.2100 & 0.2200 & 0.2761 & 0.2052 \\
8 & 0.3700 & 0.2692 & 0.0460 & 0.3500 & 0.1721 & 0.1848 \\
9 & 0.4650 & 0.1209 & 0.1033 & 0.2700 & 0.1806 & 0.2042 \\
10 & 0.2900 & 0.1518 & 0.1510 & 0.2700 & 0.2318 & 0.1948 \\
11 & 0.2550 & 0.1181 & 0.0571 & 0.3200 & 0.1636 & 0.1602 \\
12 & 0.4550 & 0.4143 & 0.2083 & & & \\
13 & 0.6200 & 0.2084 & 0.3450 & & & \\
14 & 0.4350 & 0.1308 & 0.2241 & & & \\
15 & 0.1850 & 0.0849 & 0.0564 & & & \\
16 & 0.4650 & 0.2460 & 0.2352 & & & \\
\hline
\end{tabular}

\section{Results from GC-MS analysis}

The total ion flow graph of the samples determined with GC-MS is shown in Figure 2. The major components of the volatile oils were identified through comparison with literature. The results show that phthalides were the main components of chuanxiong volatile oil, accounting for about $60-70 \%$ of the oil. The other components were terpenoids, aliphatic hydrocarbons and a small amount of organic acids. The results of analysis of chemical composition are shown in Table 3.

\section{GC fingerprint results}

The chromatograms are shown in Figure 3 and Figure 4, respectively. In view of the fact that the different chemical components have different contributions to the chemical base of chuanxiong, only the chromatogram from 9.01 $\mathrm{min}$ to $43 \mathrm{~min}$ were analyzed. The data were imported into the "Computer Aided Similarity Evaluation System" software for analysis of similarities in the chromatogram from $9.01 \mathrm{~min}$ to $43 \mathrm{~min}$. The results are shown in Table 4.

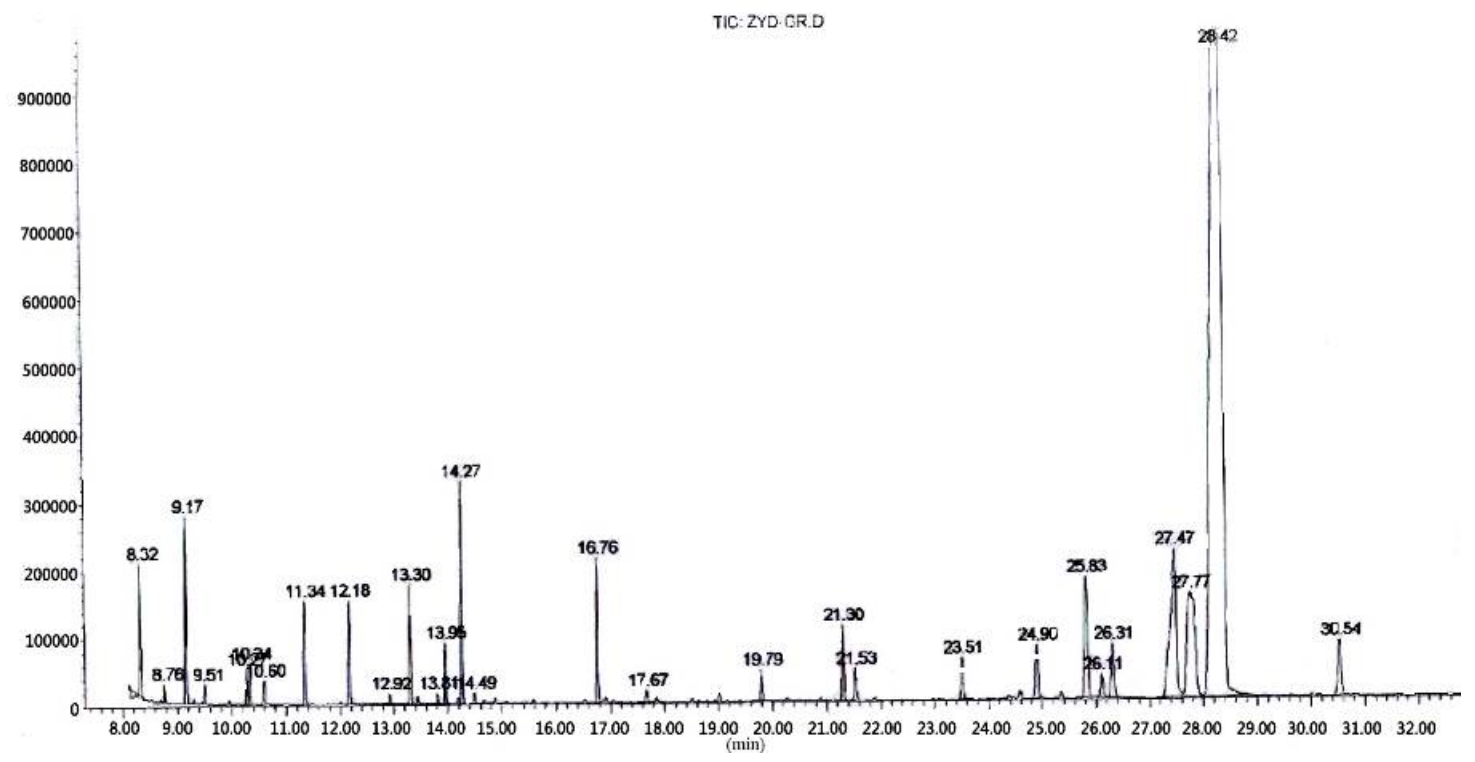

Figure 2: Total ion flow graph of volatile oils in chuanxiong samples 
Table 3: Major components of volatile oils from the chuanxiong samples

\begin{tabular}{|c|c|c|c|c|}
\hline S/no. & $\begin{array}{c}\text { Retention time } \\
(\min )\end{array}$ & Compound & $\begin{array}{l}\text { Molecular } \\
\text { formula }\end{array}$ & $\begin{array}{c}\text { Relative } \\
\text { peak area }\end{array}$ \\
\hline 1 & 8.32 & $\alpha-P i n e n e$ & $\mathrm{C}_{15} \mathrm{H}_{24}$ & 0.99 \\
\hline 2 & 8.76 & Phenol & $\mathrm{C}_{6} \mathrm{H}_{5} \mathrm{OH}$ & 0.18 \\
\hline 3 & 9.17 & Terpene & $\mathrm{C}_{10} \mathrm{H}_{16}$ & 1.88 \\
\hline 4 & 9.51 & Myrcene & $\mathrm{C}_{10} \mathrm{H}_{16}$ & 0.23 \\
\hline 5 & 10.27 & ঠ-4-Carene & $\mathrm{C}_{10} \mathrm{H}_{16}$ & 0.39 \\
\hline 6 & 10.34 & P-Cymene & $\mathrm{C}_{10} \mathrm{H}_{14}$ & 0.44 \\
\hline 7 & 10.60 & $\beta$-Phellandrene & $\mathrm{C}_{10} \mathrm{H}_{16}$ & 0.27 \\
\hline 8 & 11.34 & $\mathrm{Y}$-Terpinene & $\mathrm{C}_{10} \mathrm{H}_{16}$ & 1.16 \\
\hline 9 & 12.18 & $\alpha$-Terpinolene & $\mathrm{C}_{10} \mathrm{H}_{16}$ & 1.15 \\
\hline 10 & 12.92 & 1-methyl-4-isopropyl-2-cyclohexen-1-ol & $\mathrm{C}_{10} \mathrm{H}_{18} \mathrm{O}$ & 0.12 \\
\hline 11 & 13.30 & $(+)$-Camphor & $\mathrm{C}_{10} \mathrm{H}_{16} \mathrm{O}$ & 1.35 \\
\hline 12 & 13.81 & Amylbenzene & $\mathrm{C}_{11} \mathrm{H}_{16}$ & 0.12 \\
\hline 13 & 13.95 & 5-Ethyl-3-ynyl-undecane & $\mathrm{C}_{11} \mathrm{H}_{18}$ & 0.65 \\
\hline 14 & 14.27 & Terpineol-4 & $\mathrm{C}_{10} \mathrm{H}_{18} \mathrm{O}$ & 2.30 \\
\hline 15 & 14.49 & $\alpha$ - Terpinene & $\mathrm{C}_{10} \mathrm{H}_{16}$ & 0.10 \\
\hline 16 & 16.76 & 4-hydroxy-2-methoxystyrene & $\mathrm{C}_{9} \mathrm{H}_{10} \mathrm{O}_{2}$ & 1.39 \\
\hline 17 & 17.67 & Valerophenone & $\mathrm{C}_{11} \mathrm{H}_{14} \mathrm{O}$ & 0.13 \\
\hline 18 & 19.79 & 6-methyl-2-p-methylphenyl-heptane & $\mathrm{C}_{15} \mathrm{H}_{20}$ & 0.42 \\
\hline 19 & 21.30 & $(+)-\beta$-selinene & $\mathrm{C}_{15} \mathrm{H}_{24}$ & 1.11 \\
\hline 20 & 21.53 & Germacrene & $\mathrm{C}_{15} \mathrm{H}_{24}$ & 0.50 \\
\hline 21 & 23.51 & Spartanol (Spaihulenol) & $\mathrm{C}_{15} \mathrm{H}_{24} \mathrm{O}$ & 0.72 \\
\hline 22 & 24.90 & Butylphthalide & $\mathrm{C}_{12} \mathrm{H}_{14} \mathrm{O}_{2}$ & 1.15 \\
\hline 23 & 25.83 & Butylidene phthalide & $\mathrm{C}_{12} \mathrm{H}_{12} \mathrm{O}_{2}$ & 2.70 \\
\hline 24 & 26.31 & $(E, E)-1,3,5$-undecatriene & $\mathrm{C}_{11} \mathrm{H}_{18}$ & 1.35 \\
\hline 25 & 27.47 & Senkyunolide A & $\mathrm{C}_{12} \mathrm{H}_{16} \mathrm{O}_{2}$ & 6.90 \\
\hline 26 & 27.77 & neocindilide & $\mathrm{C}_{12} \mathrm{H}_{18} \mathrm{O}_{2}$ & 6.45 \\
\hline 27 & 28.42 & Z- Ligustilide & $\mathrm{C}_{12} \mathrm{H}_{14} \mathrm{O}_{2}$ & 63.99 \\
\hline 28 & 30.54 & E- Ligustilide & $\mathrm{C}_{12} \mathrm{H}_{14} \mathrm{O}_{2}$ & 1.34 \\
\hline
\end{tabular}

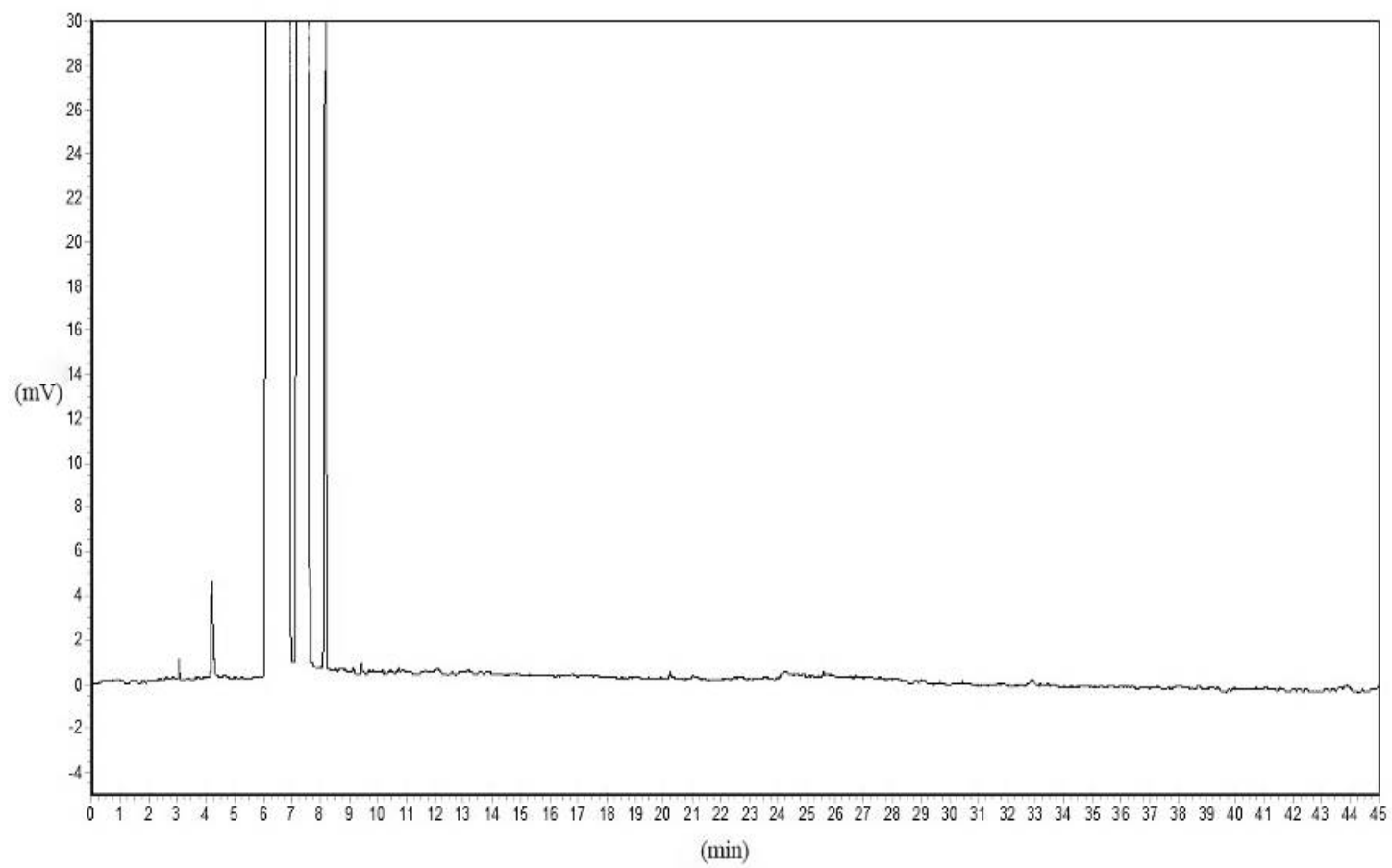

Figure 3: GC of blank solvent 


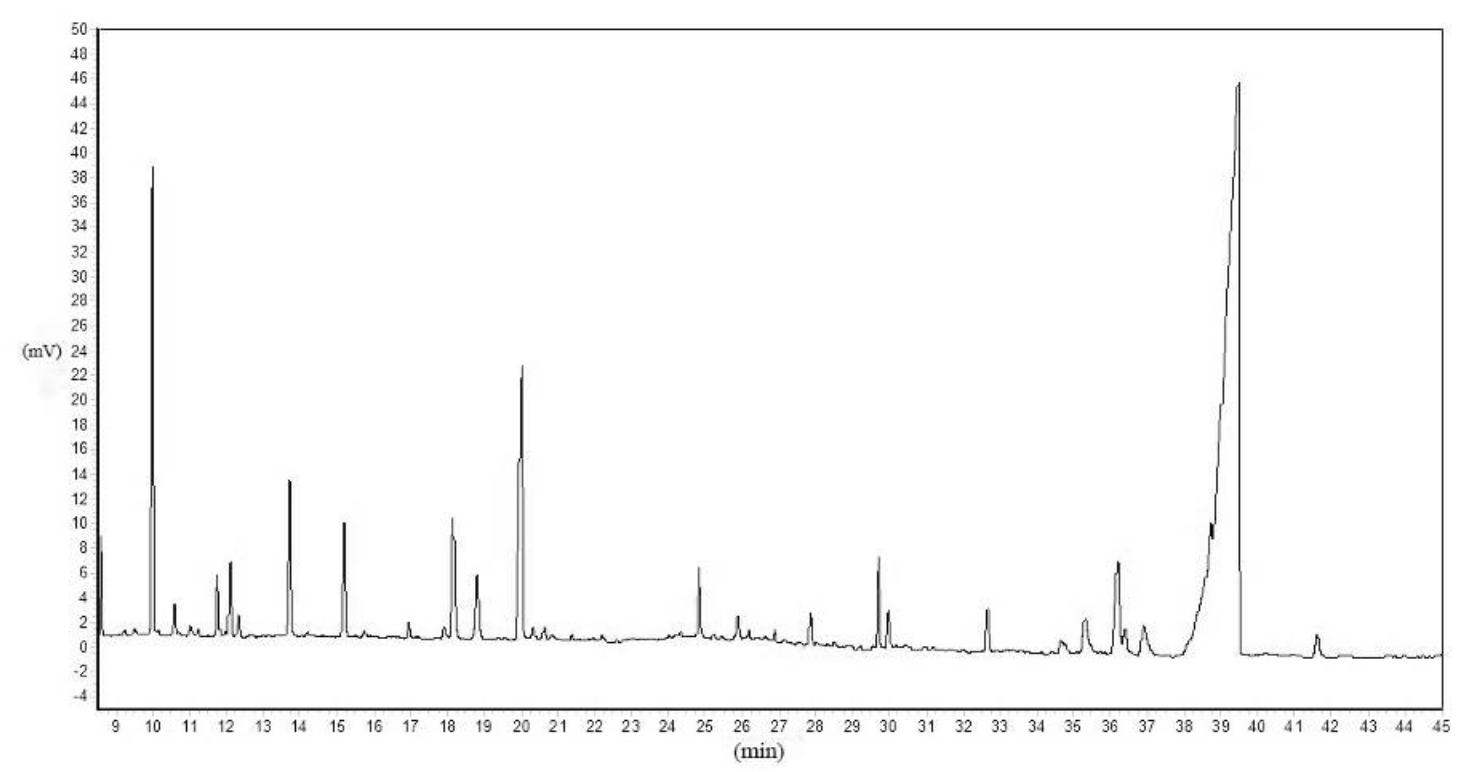

Figure 4: GC of test samples

Table 4: Results of similarity analysis of the chromatogram

\begin{tabular}{|c|c|c|c|c|}
\hline \multirow[b]{2}{*}{ No. } & \multicolumn{2}{|r|}{ Similarity } & \multirow[b]{2}{*}{ No. } & \multirow[b]{2}{*}{ Similarity } \\
\hline & $\begin{array}{c}\text { Chuanxiong from place of } \\
\text { origin }\end{array}$ & $\begin{array}{c}\text { Chuanxiong transplanted to germplasm } \\
\text { nursery }\end{array}$ & & \\
\hline 1 & 0.8505 & 0.9204 & 12 & 0.8401 \\
\hline 2 & 0.9329 & 0.9534 & 13 & 0.9039 \\
\hline 3 & 0.9258 & 0.8733 & 14 & 0.9484 \\
\hline 4 & 0.8294 & 0.9383 & 15 & 0.9235 \\
\hline 5 & 0.8968 & 0.9362 & 16 & 0.8122 \\
\hline 6 & 0.8924 & 0.9589 & & \\
\hline 7 & 0.9618 & 0.9512 & & \\
\hline 8 & 0.9372 & 0.9203 & & \\
\hline 9 & 0.9810 & 0.9440 & & \\
\hline 10 & 0.9673 & 0.9003 & & \\
\hline 11 & 0.8500 & 0.9529 & & \\
\hline
\end{tabular}

The range of similarity of chuanxiong from different places of origin was 0.8122 - 0.9810 . The similarities of chuanxiong from different places in Sichuan province were not all greater than 0.9, which indicates differences in compositions and proportions of components. The similarities of chuanxiong from Yunnan and Gansu province were less than those of chuanxiong from Sichuan province, indicating that there were large differences in composition and proportion of components. There were smaller differences among the chemical compositions of volatile oils in chuanxiong samples from different places in Sichuan. Moreover, there were some differences in chemical composition of volatile oils in different chuanxiong germplasm resources. Following transplantation to the germplasm nursery, almost all the similarities were increased. These results are shown in Figure 5.

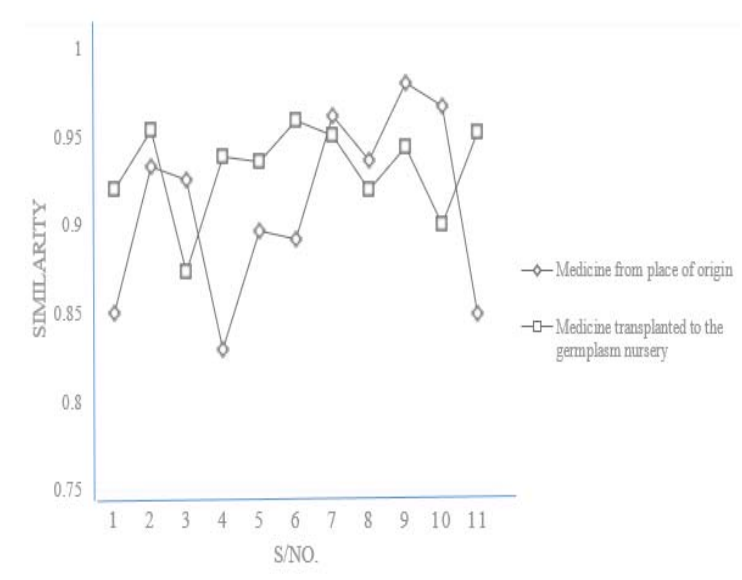

Figure 5: Graphical representation of similarities between volatile oil of chuanxiong from original planting areas and volatile oil from chuanxiong transplanted to germplasm nursery 


\section{DISCUSSION}

It has been reported that chuanxiong promotes blood circulation, activates qi, expels wind and alleviates pain [1]. Research has shown that chuanxiong exerts several pharmacological properties such as sedation and analgesia [4-6], anti-freezing $[7,8]$, cardiovascular and cerebrovascular protection [9], and antiinflammatory effect $[10,11]$. Chuanxiong is widely used in the treatment of coronary heart disease (CHD), angina pectoris [12], ischemic brain injury [13] and migraine. Studies [14-16] show that the traditional blood-activating and pain-relieving effects of chuanxiong are due to the pharmacological properties of alkaloids such as tetramethylpyrazine (TMP), phenolic acids (e.g. ferulic acid) and phthalides (e.g. ligustilide).

However, it is difficult to accurately evaluate the quality of chuanxiong through the determination of ferulic acid, TMP, and ligustilide, either separately or together. In addition, it has been reported that ferulic acid content increases with storage time because of the hydrolysis of ferulic acid conifers during storage. Therefore, it is not appropriate to control the quality of chuanxiong through determination of free ferulic acid alone. This gave rise to the concept of total ferulic acid which was developed to solve this problem in the determination of ferulic acid in Angelica sinensis [17]. Thus, in this study, based on Chinese Pharmacopoeia, preliminary experiments [18] and literature, the content of volatile oil was determined, and the contents of total alkaloids and total ferulic acid were added to comprehensively evaluate the quality chuanxiong.

According to Materia medica, the traditional and authentic production area of chuanxiong was Dujiangyan (named Guan county in ancient times) in Sichuan province. In the record of Materia medica, xiongqiong was also planted in other places apart from Suchuan, and named after its locality. For example, it is named fuxiong when produced in "Fuzhou" (now Fuzhou, Jiangxi, China), while the product from Yunnan, China is called lixiong or yunxiong. Scholars have studied the original plants, chromosomes, and chemical composition of chuanxiong from different producing areas based on Materia medica, and the results showed differences in the germplasm resources of chuanxiong. The present study compared chuanxiong from Dujiangyan and chuanxiong from other provinces. Besides, changes in volatile oil and contents of major components of chuanxiong produced in other places in Sichuan and introduced from Sichuan, were compared after transplantation to the germplasm nursery in Dujiangyan.

\section{CONCLUSION}

This study provides a comprehensive method for quality evaluation of $L$. Chuanxiong Hort. from different producing areas and comparison of different germplasm resources. The results show that the method of $\mathrm{GC}$ analysis for determination of volatile oils and main components of chuanxiong is accurate and stable for comparison of quality of chuanxiong from different producing areas. The results indicate that an authentic production area is beneficial to the generation of stable germplasm resources. The quality of chuanxiong produced in Dujiangyan was better than the quality of chuanxiong from other areas, and it may produce high efficacy in clinical application.

This study also provides theoretical basis for validation of authenticity of chuanxiong from Dujiangyan. Combined with previous research on the operational regulations of standardized production technology standards of chuanxiong, this study may lead to improved industrial advantage in the cultivation of chuanxiong in Dujiangyan.

\section{DECLARATIONS}

\section{Acknowledgement}

The authors are grateful for financial support from Science and Technology Basic Work Special Project of China (no. 2015FY111500140). "Xinglin Scholar" Academic Backbone Project for Discipline Talents Scientific Research Enhancement (XSGG-2019023) and "Xinglin Scholars" Younger Scholars Project for Discipline Talents Scientific Research Enhancement (QNXZ2019024) organized by Chengdu University of Traditional Chinese Medicine.

\section{Conflict of interest}

No conflict of interest is associated with this work.

\section{Contribution of authors}

The authors declare that this work was done by the authors named in this article and all liabilities pertaining to claims relating to the content of this article will be borne by them. Ling Chen and Jia Hou contributed equally to this work.

Trop J Pharm Res, December 2020; 19(12): 2665 


\section{Open Access}

This is an Open Access article that uses a funding model which does not charge readers or their institutions for access and distributed under the terms of the Creative Commons Attribution License (http://creativecommons.org/licenses/by/ 4.0) and the Budapest Open Access Initiative (http://www.budapestopenaccessinitiative.org/rea d), which permit unrestricted use, distribution, and reproduction in any medium, provided the original work is properly credited.

\section{REFERENCES}

1. The State Pharmacopoeia Commission of the People's Republic of China. Chinese Pharmacopoeia. Chemical Industry Press: Beijing, China, 2015, Volume 1: 40.

2. Zhang YP note. Tang Ye Ben Cao, China Medical Science Press, Beijing, China, 2011 (in Chinese).

3. Zhang C, Qi ML, Shao QL, Zhou S, Fu RN. Analysis of the volatile compounds in Ligusticum chuanxiong Hort. Using HS-SPME-GC-MS. J Pharm Biomed Anal 2007; 44(2): 464-470.

4. Lin Q, Chen JN, Lai XP, Gui SH, Fang CP, Zhao AG. The Analgesic Mechanism of Chuanxiong extract on experimental dysmenorrhea. Chin J Exper Tradit Med Formu 2011; 17 (10): 161-164 (in Chinese).

5. Yang $W$, Zeng J, Wang $X Y$, Zhang AJ. Analysis of effective analgesic and blood activating parts of Ligusticum chuanxiong by orthogonal design. Pharm Clin Chin Materia Medica 2005; 21(1): 24-26 (in Chinese).

6. Li YJ. Study on the analgesic effect of Chuanxiong extract on blood circulation. Chengdu Univ Tradi Chin Med 2009 (in Chinese).

7. Mei CN, Zeng J, Zhang LY, Liao L, Zhao JN. Study on the Quality Evaluation of Chuanxiong Rhizoma in Different Habitats on Platelet Aggregation, Coagulation in Mice, and Hemorrheology in Blood Stasis Rats. Pharm Clin Chin Materia Medica 2014; 30(2): 110-112 (in Chinese).
8. Tan S, Huang SJ. The Cerebral Protective Effect of Chuanxiong on Vascular Depression. Glo Chin Med 2015; 8(4): 492-495 (in Chinese).

9. Zhang J, Yang YF, Wu CZ, Fan SY, Xiao W, Wang ZZ. Study on the relationship between Angelica Chuanxiong medicine and supercritical extract of safflower against myocardial ischemia. Chin Tradit Herb Drugs 2013; 44(14): 1944-1950 (in Chinese).

10. Xia QS, Kong JW, Li DS, Li SS, Deng QQ, Li WF. Experimental study on anti-inflammatory and analgesic effects of Angelica sinensis and Chuanxiong Rhizoma in different ratios. J Hubei Univ Chin Med 2015; 17(6): 1-3 (in Chinese).

11. Sun $C X, W u$ GL. Study on anti-inflammatory activity and quality control of chemical constituents in Chuanxiong Rhizoma. J Med Forum 2015; 36(7): 58-60 (in Chinese).

12. Chan SS, Jones, Robert Leslie., Lin G. Synergistic interaction between the Ligusticum chuanxiong constituent butylidenephthalide and the nitric oxide donor sodium nitroprusside in relaxing rat isolated aorta. J. Ethnopharmacol 2009; 122(2): 308-312.

13. Yang $X Z$, Zeng $X X, W u T X$. Chuanxiong preparations for preventing stroke. Cochr Datab Syst Rev 2010; (1).

14. Li HX, Ding MY, Lv K, Yu JY. Determination of the active ingredients in Chuanxiong by HPLC, HPLC -MS, and EI -MS. J Liq Chromatogr R T 2001; 24(13): 2017-2031.

15. Yuan $Y$, Lin $X$, Feng $Y, X u D S$, Wang $Y H$. In Vivo Transmigration of Anti-Migrainous Compounds from Ligusticum chuanxiong Hort. Chin Pharm J 2010; 45(9): 694-697 (in Chinese).

16. Lin $H$. Protective effect of senkyunolide $A$ against rats cerebral ischemia -reperfusion injury. J North Pharm 2016; 13(4): 114-115 (in Chinese).

17. Lv GH, Chan K, Leung K, Chan CL, Zhao ZZ, Jiang ZH. Assay of free ferulic acid and total ferulic acid for quality assessment of Angelica sinensis. J Chrom A 2005; 1068(2): 209-219.

18. Jia MR. Researches on Good Agricultural Practice (GAP) of Rhizoma Chuanxiong and Radix Angelica Dahuricae Produced Sichuan. Sichuan Science and Technology Press, Chengdu, China, 2007 (in Chinese). 